\title{
Trends in Distant Student Use of Electronic Resources: A Survey
}

\author{
Kimberly B. Kelley and Gloria J. Orr
}

The University of Maryland University College (UMUC) is one of the eleven degree- granting institutions of the University System of Maryland (USM). UMUC plays a unique role among academic institutions in the State of Maryland in that it serves a large distant student population, with the proportion of students studying online approaching 50 percent of enrollments.

Information and Library Services (ILS) at UMUC conducted a needs assessment survey to examine trends in student use of library resources, services, and instruction in order to understand how student usage patterns, needs, and preferences have changed as well as stayed the same.

One important element of the survey was to obtain in-depth information on student usage patterns for electronic resources and services because (1) the library has increased delivery of these types of resources and services in the five years leading up to the current (2001) study and (2) several studies suggest that students are relying more heavily on online resources, both proprietary databases and the "free" Web. ${ }^{1}$ Therefore, ILS was interested in determining whether the shift to more online delivery of classes, and the simultaneous shift observed in user behavior in libraries in general (i.e., relying more heavily on online resources), would also affect student usage patterns and dependence on the physical library and online resources at UMUC.

The findings of the survey followed national trends and demonstrated that nontraditional, predominantly part-time students' usage patterns have changed and now favor the use of electronic resources (the Internet, in particular) and also mirror trends observed in traditional student behavior toward libraries and library resources in many important respects.

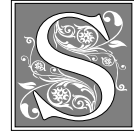

tudent reliance on the Web and online resources continues to rise at a rapid pace. Recent studies confirm that student usage patterns are shifting and student preference for using online resources is becoming predominant on college cam- puses. $^{2}$ This shift to reliance on online resources both interests and alarms many librarians and faculty. For example, several recent articles have lamented student reliance on online resources, citing the students' inability to properly evaluate what they find, their lack of understand-

Kimberly B. Kelley is the Associate Provost, Information and Library Services, at the University of Maryland University College; e-mail: kkelley@umuc.edu. Gloria J. Orr is the Director of Information and Library Services at the University of Maryland University College; e-mail: gorr@umuc.edu. 
ing of how little is actually available via the Web, their unawareness of the lack of currency and relevancy of Web resources, and the increased temptation to plagiarize or inadequately cite materials found. ${ }^{3}$ Jonathan J. Kandell has been quoted as saying, "college students as a group appear more vulnerable to developing a dependence on the Internet than most segments of society." 4 The concern and interest in understanding student usage patterns of libraries and their resources and services is becoming an important factor in how librarians select formats for delivering their resources, offer services (e.g., whether online chat will reach more students than a face-to-face interview), and instruct their user population to be informed consumers of all types of information, especially information found on the Web. There is general consensus that the Internet is here to stay, and realizing its potential for college students and determining how to address the issue with students effectively are two of the major issues facing the library profession today.

The UMUC student population offers an informative look at nontraditional student use patterns of library resources, services, and instructional materials. Because UMUC has approximately as many students in the traditional, face-to-face classroom as in the online classroom, and because the majority of students are parttime, the student usage patterns observed provide insight into how a rapidly growing sector of students is addressing their information needs. The usage patterns observed also provide information on student preferences and trends in their use of libraries and library resources that have relevance for librarians serving this and other types of student populations.

\section{Purpose of the Study}

The purpose of the UMUC needs assessment survey was threefold: (1) to identify student awareness and use of, and perceived needs for, physical libraries, delivery of library materials, instructional and promotional services, resources and technologies; (2) to assess the extent of student use of electronic resources; and (3) to compare findings, where possible, with the 1996 needs assessment conducted by the Office of Library Services.

\section{Research Questions}

The survey asked questions relating to perceived needs and awareness and use of services. The following are the research questions the survey was designed to answer:

1. Which libraries are students using most frequently, and why? Do students report that these facilities are meeting their needs?

2. Which library services do students perceive as important?

3. Which instructional methods do students prefer for library-related skills?

4. How useful do students consider the library instructional and informational materials offered by UMUC?

5. What factors do students perceive can motivate them to use libraries?

6. What factors affect the way students feel about using libraries?

7. What are the best ways of communicating information about library services and resources to students?

8. Are students using electronic resources? If so, are they accessing them remotely or in the library?

\section{Methodology}

The research design for the current survey was based on the previous survey instruments developed by the Office of Library Services and distributed in the spring of 1996 and the fall of 1989. The current survey used a random sample, stratified by graduate and undergraduate students located within the continental United States.

In the fall of 2001, a combined total of 21,121 graduate and undergraduate students were enrolled in UMUC stateside programs. The authors gathered a random sample of 13 percent of the student population to use as the sample for the survey. Thirteen percent of the student population encompassed 2,713 students: 1,961 undergraduates and 772 graduate 
students. Thirteen percent of the student body was chosen because it was the percentage recommended by UMUC's Office of Institutional Research (OIR). OIR recommended this figure because it would result in a sufficient sample population for analysis, reached a significant number of students, and was not so large that it would overly burden UMUC's student population, who are surveyed frequently. Although 13 percent is not a large percentage, it is large enough to generalize the results of the survey to the larger student population.

\section{Survey Instrument}

The survey instrument used for this study was based on the 1996 survey. In August 2001, the authors reviewed and revised the 1996 survey to ensure that it would sufficiently address student use of electronic resources and services and to remove or update outdated information as necessary. ${ }^{5}$ The purpose of the survey instrument was to answer the research questions cited at the beginning of this article.

Many of the survey questions used for this study were identical to those asked in 1996. The authors made a few changes in the current survey to address the changed, more technologically oriented environment in 2001. For example, one new question asked students where they accessed electronic resources because the authors thought they would see greater usage outside the library. A second new question asked students about their use of the "free" Web, something that had not been asked about separately in previous surveys. The authors decided to ask about library database use separately from "free" Web use because so much has been written on student reliance on the free Web. Therefore, the authors wanted to get a sense of the degree to which students were using free Web resources separately from the library's online resources.

\section{Mailing Procedures}

The survey was mailed to the sample population on November 7, 2001. The mailing consisted of a cover letter signed by the associate provost, ILS; the student questionnaire; and a self-addressed, stamped envelope to use to return the survey to ILS. The mailing amounted to 2,713 surveys, which respondents were asked to complete and return by November 19, 2001.

Respondents were deleted from the database as their surveys were received. A second mailing was sent on November 30 to those students who did not respond to the initial mailing, requesting return by December 17, 2001. Between January 22 and 25, 2002, a random sample of 251 students were contacted by telephone and asked to complete the survey during the telephone call from an ILS staff member. This was done to increase the response rate to the minimum needed for statistical analysis. Eleven students completed the survey in this manner.

\section{Response Rate}

The overall response rate was 30 percent (27.5\% for undergraduates and $36.5 \%$ for graduates). The number of respondents totaled 813 .

\section{Results of the Survey Data}

The results of the study are presented below as answers to the eight research questions presented earlier in this article.

\section{Research Question 1}

Which libraries are students using most frequently, and why? Do students report that these facilities are meeting their needs?

To answer this research question, the following survey questions were used as the basis for evaluating student library use behavior:

- Survey question 4, "During a semester, how often do you visit a library to complete course-related assignments?"

- Survey question 5, "When you do visit a library, which library do you visit most often to complete course-related assignments?"

- Survey question 6, "Please rank the quality of library services and materials in the library you visit most often." 


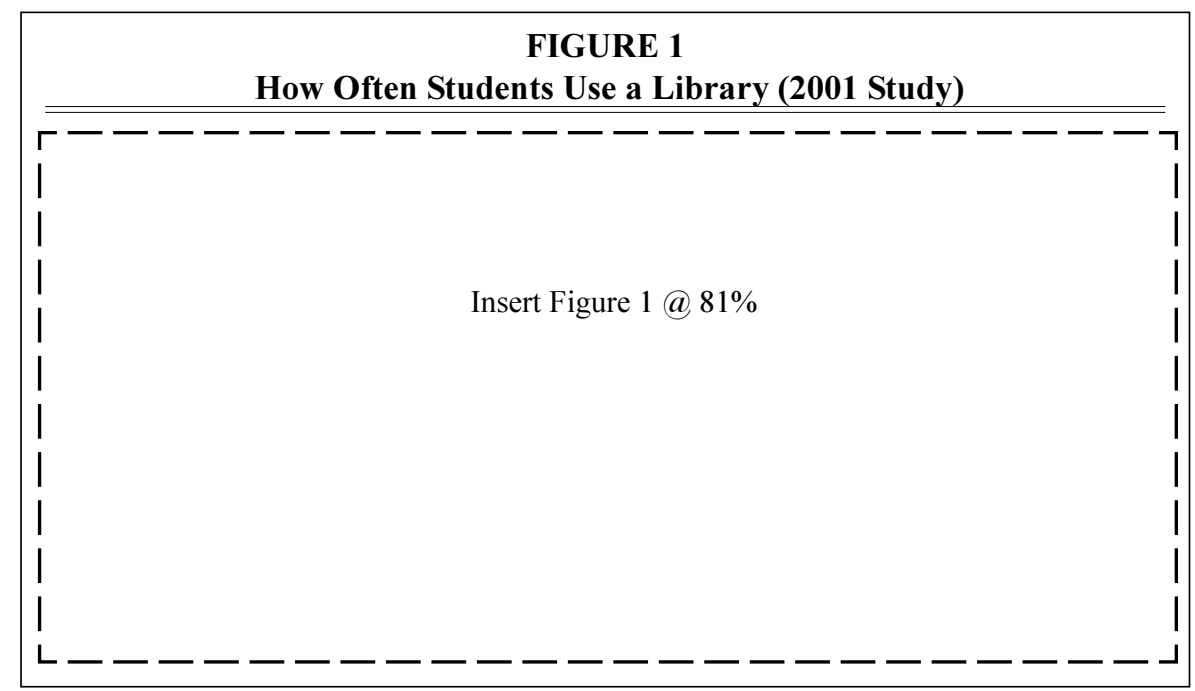

Sixty-six percent of respondents reported they "seldom" or "never" visited a library versus 32 percent who reported they "frequently" or "often" used a library. (See figure 1.) The number of respondents reporting they use a library "seldom" or "never" is higher than in the 1996 survey. The results of the 1996 survey indicated that 48 percent of respondents "seldom" or "never" used a library. (See figure 2.) Therefore, a greater percentage of students are reporting that their use of a library facility is less than it was five years ago.

Between the 1996 and 2001 surveys, there has been a significant change in the makeup of the student body. In the 2001 survey, 59.7 percent of respondents indicated they were taking most of their courses via a UMUC course management system, WebTycho, and 40.3 percent reported taking their courses in a classroom. In contrast, in 1996, 18.9 percent of students reported taking most of their courses us-

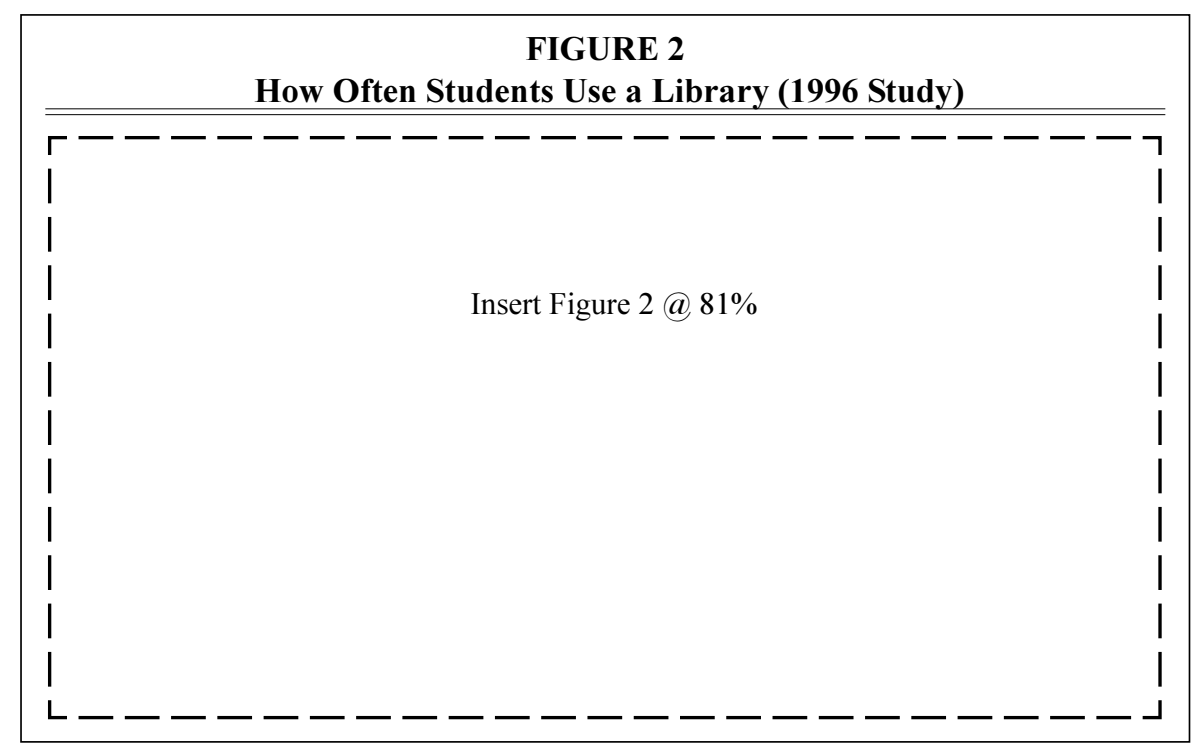




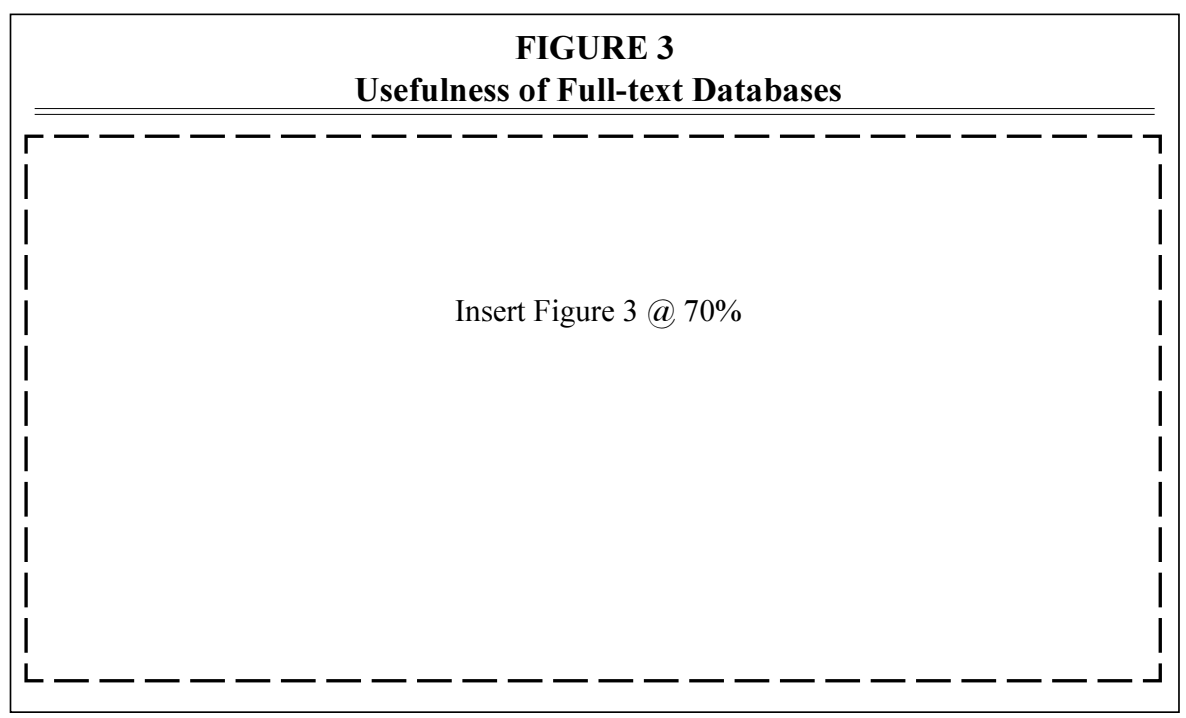

ing a course management system and 81.3 percent reported taking most of their courses in a classroom. Students studying in a classroom are significantly more likely to visit a library than their counterparts studying online, according to a chi-square test of independence $(\mathrm{p}<.05)(\mathrm{N}=813)$. In view of this, the shift in student use of the library mirrors the movement of students from taking the majority of their courses face-to-face to studying online.

\section{Research Question \#2}

Which library services do students perceive as important?

To answer this question, an analysis was done of the results of survey question 8 , "Using the scale below, please indicate the usefulness of the following services provided by UMUC in assisting you to complete library-related assignments." Nine services were listed within question 8 that students were asked to measure in terms of their usefulness in completing libraryrelated assignments. The nine questions asked students about instruction, access to library staff, access to library services, remote access to several electronic services, and book delivery and document delivery. The purpose of question 8 was to determine which services offered by ILS are most useful and which ones are least useful.
Of the nine services listed, the greatest percentage of respondents $(51.2 \%)$ indicated that off-campus access to full-text materials in the library's databases was the most useful service. (See figure 3.) The second most useful service $(51.1 \%)$ was off-campus access to the library's online library catalog. (See figure 4.) These data confirm anecdotal findings by the librarians that students consider access to resources off-campus to be extremely useful. This finding also confirms that the investment the university has made in increasing the number of databases the library offers, emphasizing full-text offerings, is an important service that is justified by student self-reported needs and preferences. Students indicated that the availability of full-text resources from offcampus are important for completing their course-related assignments and being successful at UMUC.

When the authors examined the survey results, it was noted that a large percentage of undergraduates were "not aware of" the availability of the library's online resources. (See figure 3.) This lack of awareness was attributed to several factors, including:

1. Students are widely dispersed across the State of Maryland and the United States so their knowledge of the library may be less. 


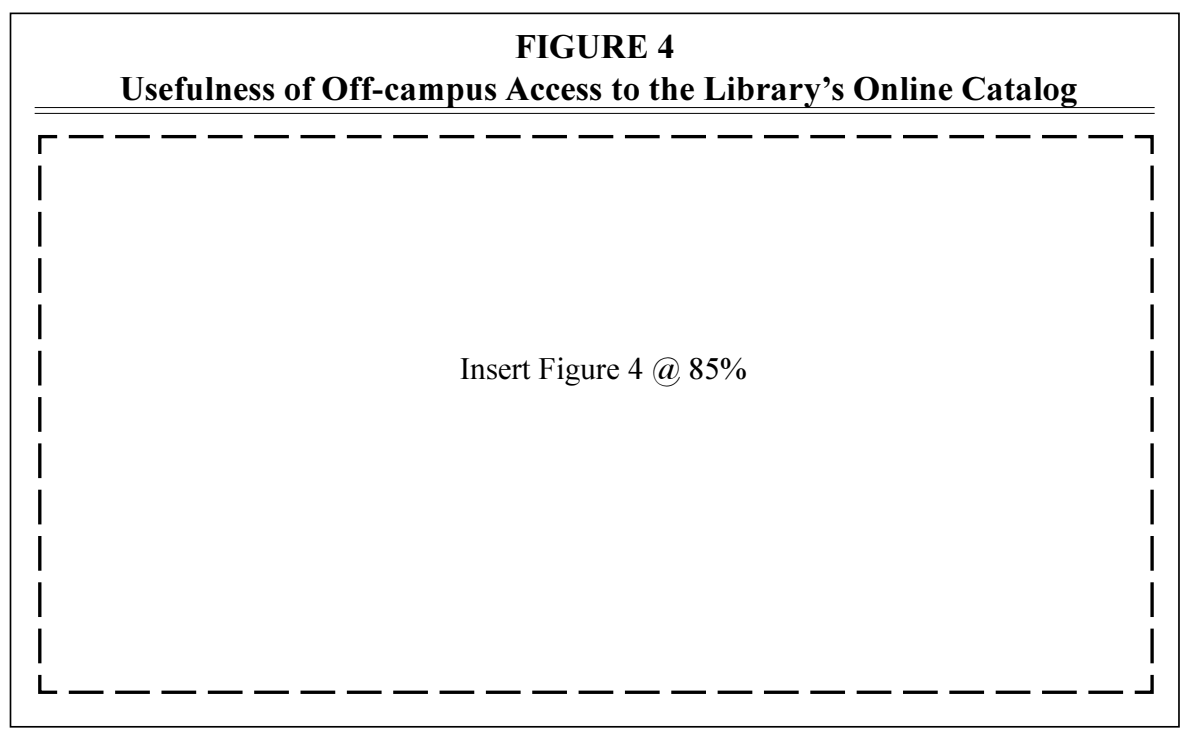

2. There has not previously been a required course about the library and its resources for undergraduates.

3. There is much wider student knowledge of the "free" Web, and students tend to prefer to use it.

Six years ago, the authors implemented a required course in the graduate school and saw a significant rise in graduate student knowledge of the resources available to them in this survey. In 2001, in collaboration with the School of Undergraduate Studies (SUS), a new, required online course was launched for all undergraduates. In view of this, the authors believe that the addition of the required course in SUS will significantly impact the level of student awareness of the library when the next survey is conducted in five years.

\section{Research Question \#3}

Which instructional methods do students prefer for library-related skills?

To determine how to best provide students instruction in library-related skills, survey question 12 was analyzed. The question asked students to rate different methods of delivering library instruction including Web-based tutorials and guides, a for-credit course delivered online or in the classroom, a noncredit workshop offered face-to-face or online, and instruction delivered via videotape or through paper handouts. Overwhelmingly, students reported that Web-based tutorials or guides were the most popular formats for receiving instruction in library resources and services $(71.7 \%)$. The preference for delivery via an electronic format was first observed in the 1989 survey and again in the 1996 survey. In 1989, students considered computer-aided instruction their first choice. In 1996, 74 percent of student respondents selected computer-based instruction as their preferred method of receiving instruction. The trend continued in the 2001 survey. The data indicated that the technologies may change but, at the same time, students overwhelmingly prefer to have instruction delivered in a format that is accessible off-campus and offers them flexibility in when they receive instruction. The flexibility offered by the online environment is obviously of great importance to UMUC's student population, and student acceptance of this format appears to be very high and consistently preferred over the fifteen-year period the survey has been repeated. This high acceptance also suggests that student participation and satisfaction are likely to be higher using an online format. 
Students were not in favor of noncredit offerings. Only 18.9 percent strongly or moderately agreed that a noncredit workshop would be a useful way to receive library-related instruction. As a result, similarly to the 1996 survey, the results indicated that library instruction should be online and for credit to ensure the greatest level of student participation and acceptance.

\section{Research Question \#4}

How useful do students consider the library instructional and informational materials offered by UMUC?

To provide an answer to this question, survey questions 12 and 13 were analyzed. Survey question 12 dealt with students' opinions on the usefulness of different instructional delivery methods. Question 13 measured the extent to which different resources offered by ILS were useful to students in completing courserelated assignments.

In the survey, students rated Webbased tutorials and guides as being the most useful publications ILS offers $(71.7 \%)$. The desire for tutorials or guides on how to use technology resources has continued from the 1996 survey into the
2001 survey. In both 1996 and 2001, students reported being eager for materials that would assist them in using the library's electronic resources more effectively. Further, in question 13, students indicated that the two most useful publications ILS offers are its Web-based tutorials $(50.8 \%)$ and Web-based instructions for using the online catalog $(49.3 \%)$. The results of the last two needs assessment surveys indicated that technology-based guides, focusing on electronic resources and their use, are of greatest usefulness to students.

\section{Research Question \#5}

What factors do students perceive can motivate them to use libraries?

To determine the factors that motivate students to use libraries, question 14, "I would use libraries and information resources (online or in a library) more often if," and question 7, "Keeping in mind the library you visit most often, please use the scale below to respond to the following statements," were analyzed. Question 14 offered students six choices, including: if students were given more assignments, if a library were closer to home, if library research was easier, if the student felt

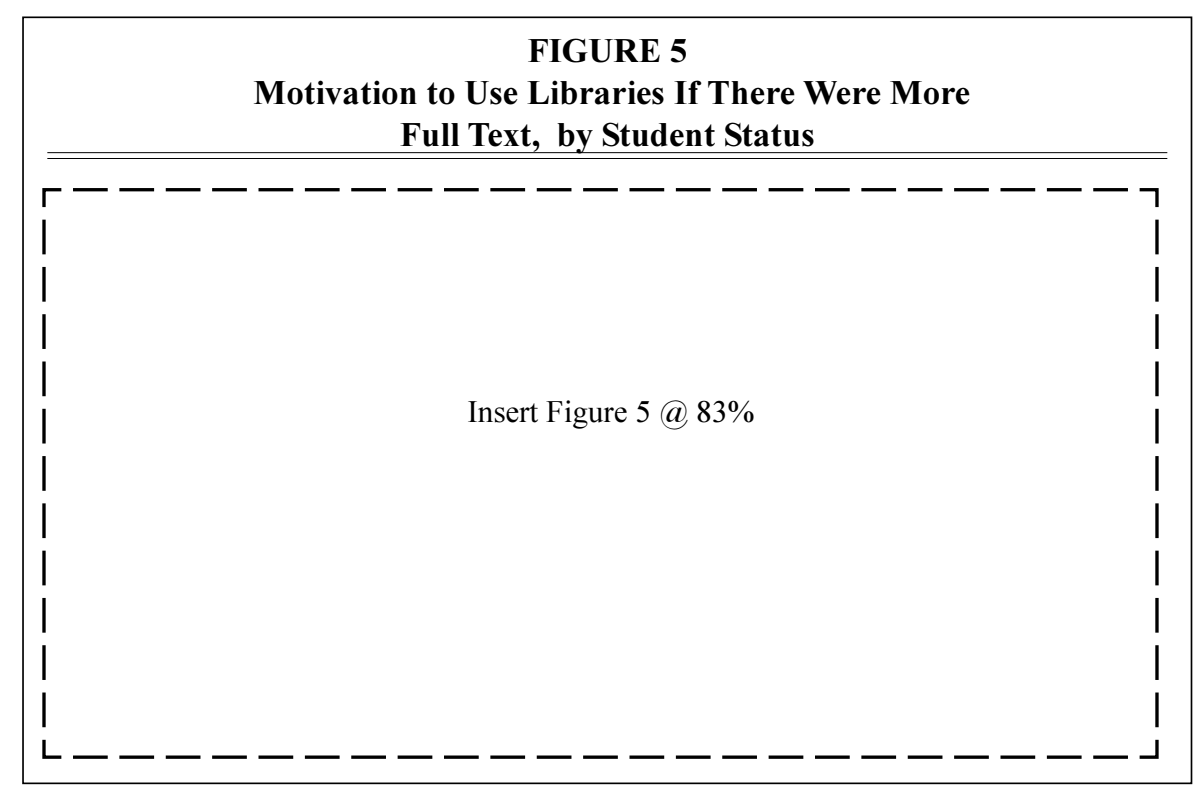




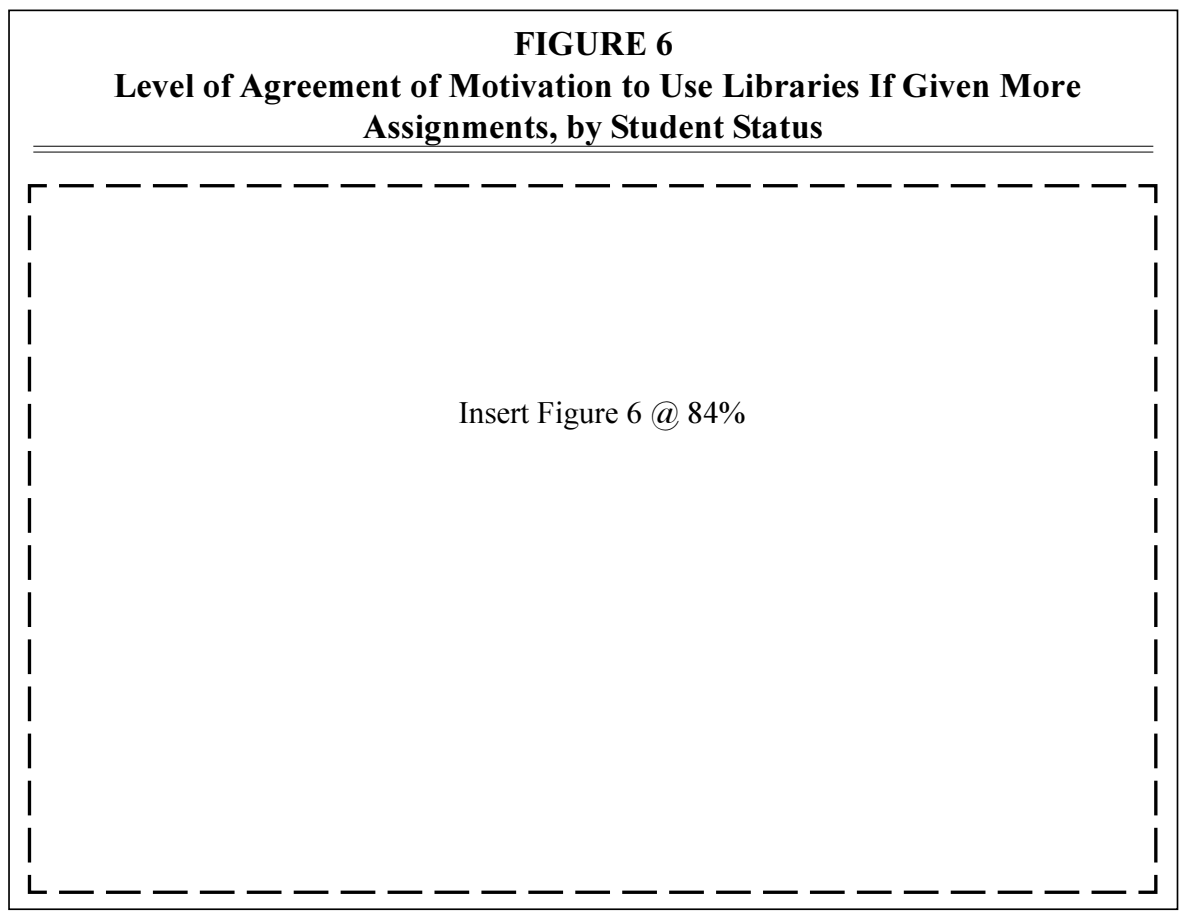

more confident, if library research was less time-consuming, or if more information was available full-text on the Web. For question 7 , students were asked whether they agreed with the following:

- Libraries are overwhelming because of the quantity of information they contain.

- Libraries are overwhelming because of computers and electronic databases.

- Books are seldom on the shelf.

- It is too time-consuming to use libraries.

- Locating books and/or journals is difficult.

- Libraries are ideal places to study.

- Librarians are helpful.

Both questions 7 and 14 explore the reasons that students are more or less motivated to conduct library research and visit libraries.

In 1996, when question 14 was analyzed, the top reason students reported for being motivated to use libraries was if an appropriate library was closer to their home $(69 \%$ of undergraduates and $65 \%$ of graduate students). In 2001, the top reason students thought they would be more motivated to use libraries was if there were more full-text online $(71.7 \%)$. (See figure 5.) The 2001 survey demonstrates that the availability of full-text information online is a primary motivating factor for UMUC students to engage in library research. Interestingly, the availability of a library close to home remains an important motivator. In the 2001 survey, the third most important factor motivating students to visit libraries or do research was the availability of a library close to home (51.8\%). It is not surprising that the importance of a library close to home has lessened in the 2001 survey. The previously stated finding that fewer students are using libraries and more students are doing their research online would support this trend. However, the availability of a library near home is still an important factor, although less so than in 1996.

The second most important motivating factor in 2001 was if students were given more assignments (60.1\%). (See figure 6.) In 1996, respondents also rated more assign- 
ments as being a primary motivating factor, with 64 percent responding that they would use libraries and library resources more often if given more assignments. So, the trend continues that students would be more motivated to do research if given more assignments by their instructors that required the use of library resources.

In examining question 7 , the findings do not indicate that a significant proportion of students reported that they cannot find books or that they find libraries overwhelming. Further, the majority of students reported that libraries are excellent places to study and that library staff is helpful. These findings suggest that the library's resources, services, and staff are not discouraging students from visiting the library. As a result, the survey results suggest that usage of library resources, services, and instructional materials has more to do with the curriculum and course assignments than with any difficulties students experience using libraries.

\section{Research Question \#6}

What factors affect the way students feel about using libraries?
To answer research question 6, survey questions 6 and 7 were analyzed. Survey question 6 asked students to measure the quality of the resources and services at the library they use most often. Survey question 7 asked students to respond to a series of questions that asked them how they feel about using libraries and whether they find some aspects of using a library overwhelming. For survey question 7 , the percentages of students who are overwhelmed by libraries has dropped from the 1996 survey. In 1996, 35 percent of undergraduates and 45 percent of graduates reported they thought locating materials in the library was difficult. In contrast, in 2001, 19.3 percent of respondents reported that they thought finding materials in the library was difficult, a significant downward trend. Very few students reported thinking that libraries are overwhelming.

Survey question 6 asked students to rank the quality of the services and materials in the library they use most often. In the 2001 survey, as reported previously, 53.7 percent of respondents indicated that the library they use had "excellent" or

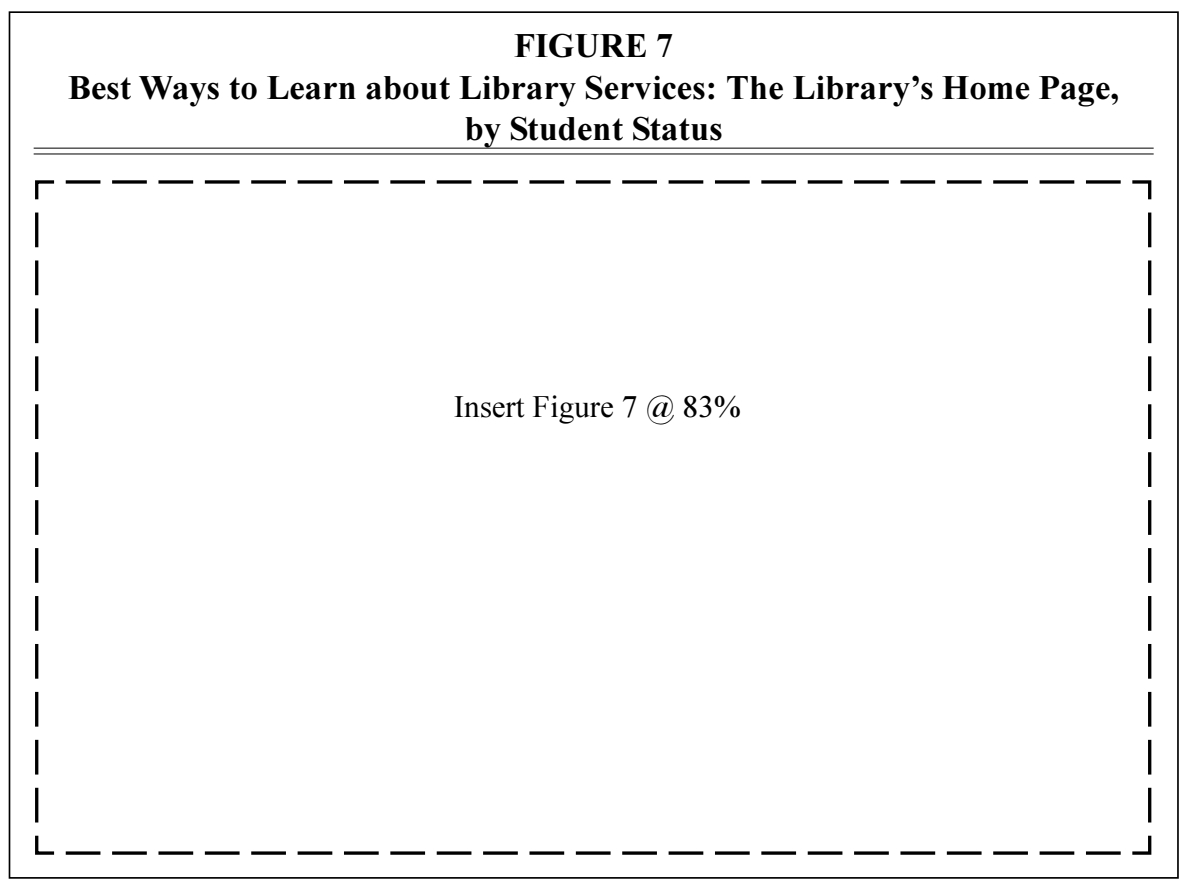




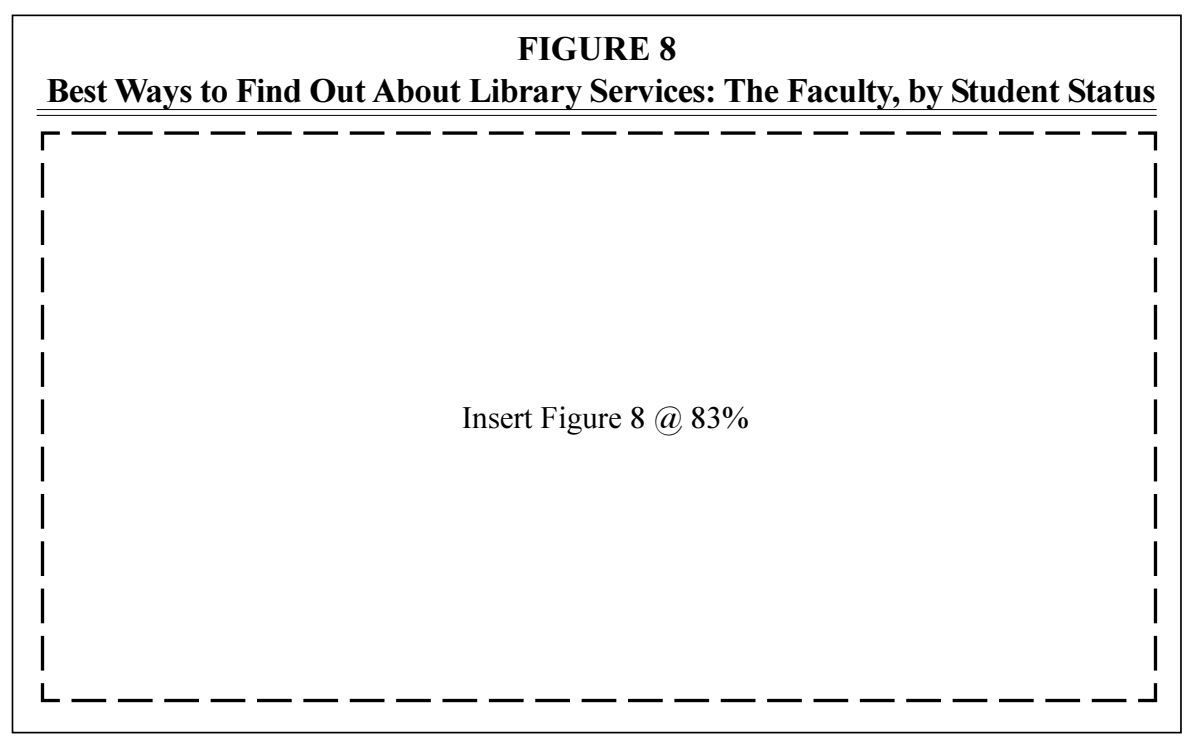

"good" quality services and resources. However, students' levels of satisfaction with the library they use most often are less than in 1996. Although it is difficult to determine why this is so, the authors consider the fact that fewer students are using the library to partially explain why satisfaction has declined. Fewer students responded to the question because significantly fewer students are using a library at all. Therefore, their ability to evaluate the quality of the physical library also is less.

Moreover, using a library is likely to be more difficult than conducting a search on the "free" Web. The majority of students prefer the Web for ease of use, regardless of the quality of what they find. In contrast, the library usually provides better resources, but identifying them is likely to be more time-consuming and students are thus less likely to report high levels of satisfaction.

In addition, students may be selecting a library that is inappropriate for their needs, resulting in dissatisfaction with the quality of what they find. For example, if a graduate student visits a local public library rather than the on-campus library, she or he may be disappointed in the resources and not understand that the public library is incapable of providing the necessary resources for graduate-level library research. Therefore, students' satisfaction would be less and their evaluation of the library's quality would decline.

\section{Research Question \#7}

What are the best ways of communicating information about library services and resources to students?

To determine the best way to communicate with students, survey question 16 was analyzed. Survey question 16 asked students to evaluate six choices for receiving information which were: (1) student publications, (2) direct mailings, (3) UMUC instructors, (4) materials at the teaching sites, (5) online information via UMUC's home page, and (6) other.

In the 2001 survey, the most effective means to reach students, in the view of respondents, was through the UMUC library home page $(62.7 \%)$. (See figure 7 .) This finding strongly suggests that the library needs to ensure that its home page is current, is updated regularly, and provides information in a format that is helpful to students because they consider this source of information the most effective means for reaching them.

As with 1996, however, the 2001 survey also had UMUC faculty as the second most popular choice for learning 
about library services and materials. (See figure 8.) Sixty percent of respondents overall indicated that they thought their instructor was one of the best ways to learn about the library. This finding would suggest that a close linkage between librarians and instructors is important to ensure that students have the information they need about the library.

\section{Research Question \#8}

Are students using electronic resources? If so, are they accessing them remotely or in the library?

To answer the question concerning student use of electronic resources, questions 9, 10, and 11 were analyzed. Question 9 asked students about how often they used the electronic resources available through UMUC, question 10 asked students about the frequency of their use of the free Web, and question 11 asked students how often they used electronic resources of any type remotely from the campus.

For question 9, which asked about the library's databases, 44.5 percent of students indicated they used the resources frequently. In 1996, the figure was similar with 40.4 percent of respondents indicating they used the databases available. Interestingly, a chi-square test of independence for the survey results reveals a significant difference between undergraduates and graduates in their use of the databases. Based on a chi-square test of independence, graduate students are significantly more likely to use the databases than their undergraduate counterparts. When analyzed by student status, 69 percent of graduates, as compared to 32 percent of undergraduates, use the databases frequently. (See figure 9.)

In addition, although students taking the majority of their courses online report lower usage of the physical library, according to a chi-square test of independence, their usage of the library's databases is significantly higher than their counterparts taking the majority of their courses in the classroom $(\mathrm{p}<.05)(\mathrm{N}=813)$. Therefore, the survey results indicated that students taking their courses online are more likely to use the library's databases and are using them more often than those students taking courses face-to-face.

Question 10 asked specifically about use of the free Web. Overall, 77.6 percent of students indicated they use the free Web frequently during the semester. This finding is important because it confirms the extent to which students rely on the free Web. Reliance on the free Web is high among both undergraduates and gradu-

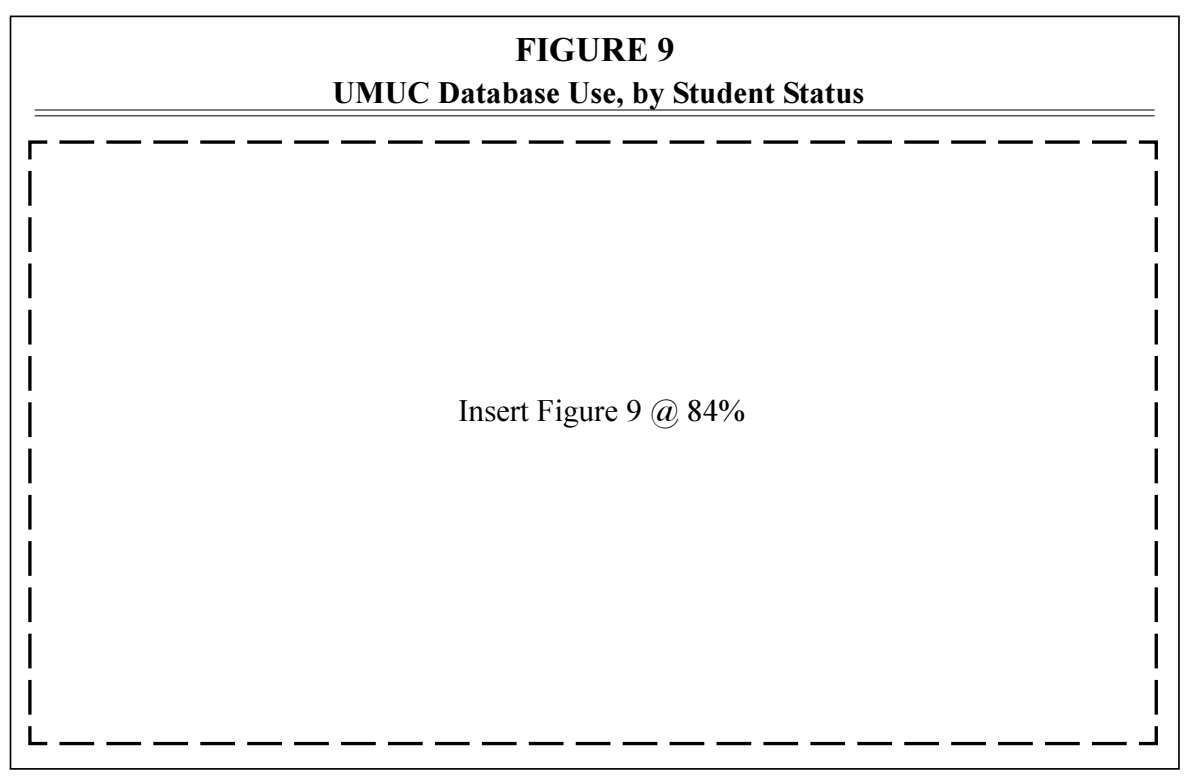




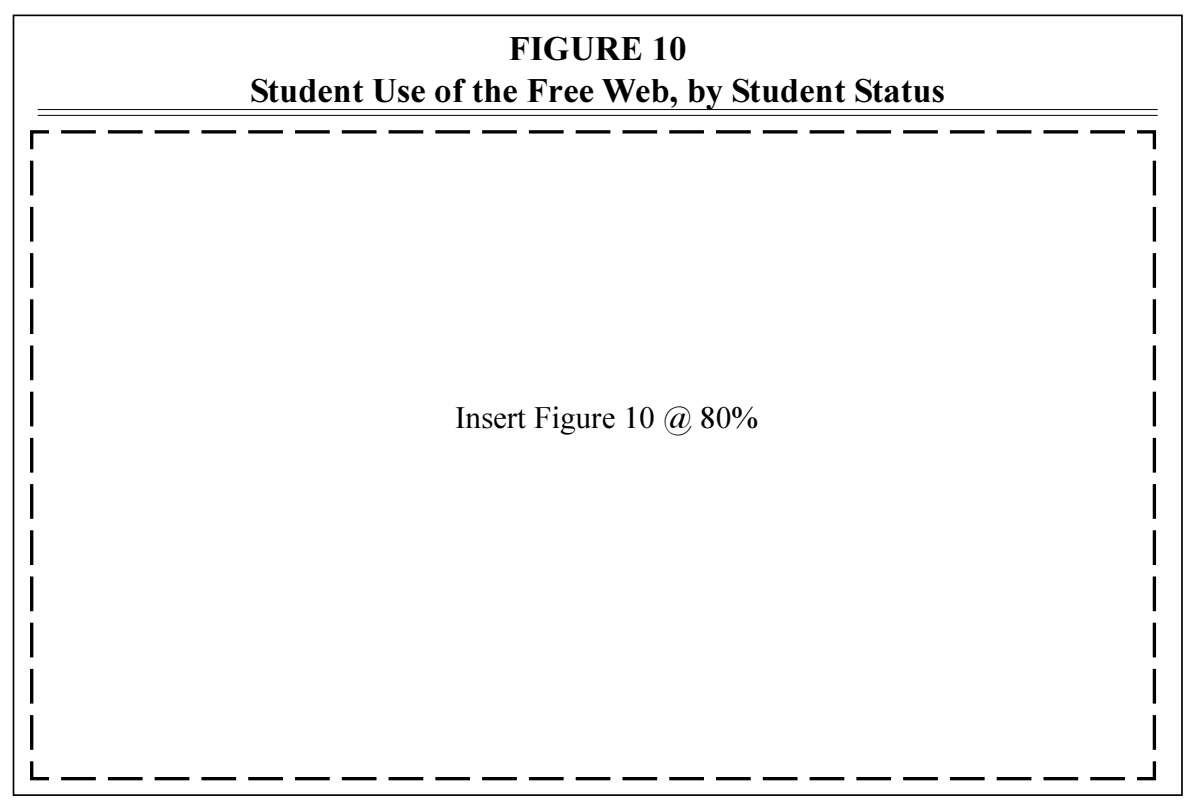

ate students. Use of the free Web was significant based on a chi-square test of independence $(\mathrm{p}<.05)(\mathrm{N}=813)$. Fifty-six percent of undergraduates and 71 percent of graduates indicated they use the free Web frequently (i.e., three times a month or more). (See figure 10.) The finding that a large percentage of UMUC students use the free Web provides strong evidence that the library's programs designed to teach students how to be informed consumers of information via the free Web is an important part of the library's instructional program.

The study results indicated that free Web usage is popular among all types of students, regardless of whether they are studying online or face-to-face. Students studying online were no more likely than students studying in the face-to-face classroom to use the free Web.

Question 11 explored where students are accessing electronic resources. Eightyone percent of student respondents indicated they are using the electronic resources offered by UMUC from an offcampus location such as home or work. This finding confirms that students are not coming as often to the library to use resources and prefer to use them at a loca- tion that is convenient for them. When examined by student status, both undergraduates and graduate students use resources remotely as the preferred method of using library resources and services. Undergraduates use resources off-campus at higher levels than graduate students, but both groups are using resources remotely in very high numbers. (See figure 11.)

The responses to the survey indicated that, overwhelmingly, students are using electronic resources as the preferred means of doing library research. Further, they are accessing these resources primarily from off-campus locations.

In addition, the findings indicated that the library must continue and enhance its program to educate students about using the free Web effectively and encourage greater use of the library's databases. Recent publications, such as the CLIRinghouse, reported that a recent study at the University of California, Los Angeles, found that four out of five college freshmen click on the Internet when looking for resources for their homework. ${ }^{6}$ In a recent Washington Post article, Laura Stepp reported that students rely primarily on the Web for their research needs and that their faculty are having a difficult time educat- 
ing them about the limitations of material found on the Web. ${ }^{7}$ The number of articles that discuss the problem of student reliance on less than high-quality information on the free Web is extensive.

As a result, it is not surprising that UMUC students are following this national trend and that their primary means of accessing information is via the free Web. At the same time, it also means that UMUC instructors and librarians need to continue to educate students about the advantages and limitations of the free Web and to work to increase the number of students using the library databases to ensure a well-rounded information-literate student who is aware of and utilizes the best resources available, not just those that are quick and easy.

\section{Conclusions}

The results of UMUC's needs assessment survey indicated that student use of a physical library facility is significantly less than it was five years ago and that, of those students who use the physical library, undergraduates report using it more often than graduate students do. Further, physical library use is signifi- cantly higher among those students who take the majority of their courses face-toface. Students who take the majority of their courses online are not using the physical library as often.

The finding that usage of the physical library is decreasing indicates that, as other studies have found, students are relying less on the physical library and to a far greater degree on online resources available outside the library's walls. ${ }^{8}$ For example, data from the Association of Research Libraries (ARL) show that students nationally are reporting that their use of the Internet is 73 percent whereas face-to-face reference queries at university libraries have dropped precipitously since the late 1990s. ${ }^{9}$ The fact that students are using the facilities less than in previous surveys demonstrates that UMUC student usage behaviors are following national trends. Further, students studying online are significantly less likely to use a library, a finding that is not unexpected because many students who are studying online tend to be in areas where libraries may not be readily available.

The survey finding that students are using libraries less, coupled with other na-

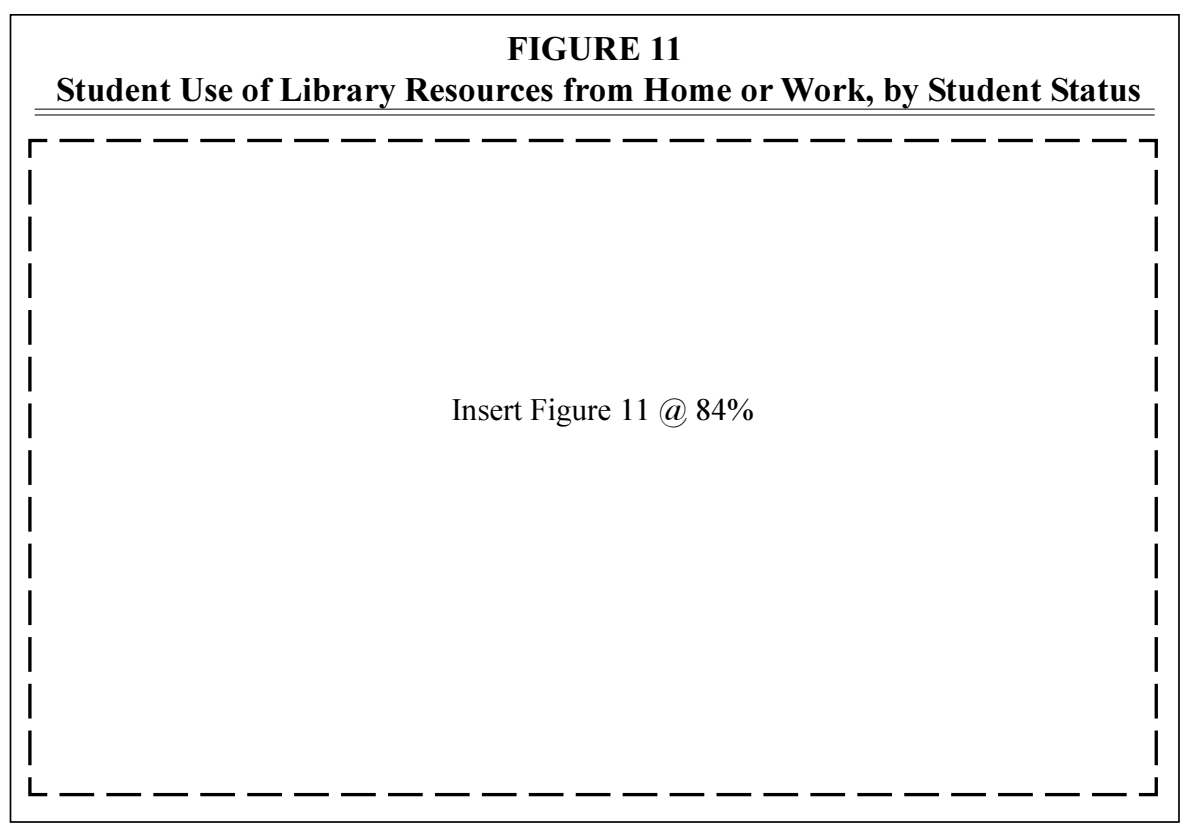


tional study results, suggests that academic libraries in general need to determine how patterns of Internet use are affecting the makeup of the physical library's primary clientele to ensure that the services offered within the library are those most needed by that clientele. Librarians also need to examine how to make the physical library more attractive and relevant to students who have numerous other options and show a propensity to spend very little time in the physical library building. A recent article stated that "well-trained staff who understand the value of customer service can make all the difference in giving users a reason to come to the library, rather than turning to a competitor."10

In addition, librarians need to consider how the library's resources, services, and instruction programs are altered to meet the needs of the whole of their user population, particularly those students and faculty who are using the library building less but still need assistance to use the library's resources, services, and instructional capabilities effectively. Studies such as the one at UMUC, and others reported in the literature, demonstrate that the need to evaluate how the library provides service has never been greater and new challenges and opportunities face librarians in determining how to address students' and faculty members' needs successfully. Less is known about how to reach students who are studying primarily online. More work needs to be done to meet the online student population's needs and to find new means to reach students that do not require a visit to the library to receive services.

Students also reported that remote access to full-text materials and citation and abstract databases are the most important services offered by the UMUC library. This survey finding confirms that, as with other published studies, students are highly focused on using Web-based resources and prefer electronic resources to other types of resources the library provides. ${ }^{11}$ Respondents consistently reported that electronic resources were the most useful and their preferred method to receive instruction online, and they placed a high premium on access to full-text materials. Further, students considered the availability of more full-text information on the Web to be a primary motivating factor in their use of libraries. This trend is not unique to UMUC. In another recent study, the authors found that students visiting a library showed a definite preference for using electronic resources, consistently selecting them in preference to citation indexes. ${ }^{12}$ Another study found that students would often wait online for access to electronic resources rather than use identical paper resources. ${ }^{13}$ Thus, the trends found in UMUC's nontraditional student population mirror the behavior of students at a traditional campus who have access to a physical library facility and ready availability to paper and electronic resources. The obvious behavioral similarities observed among nontraditional and traditional student populations reinforces the importance of continuing to implement services that are independent on the physical library building and offer more transparent access points for users. For example, offering more links to Web sites and electronic documents in the online catalog is one service that would make the libraries' resources more accessible to anyone, whether in the library or accessing resources remotely.

Creating a more comprehensive online catalog is one important means of providing a filtering mechanism for students which librarians currently provide for print resources, but which is not available for the majority of Web resources used by students. Making more Web resources available through the online catalog will help students to evaluate the sites more critically and make the sites more accessible to students both within and beyond the library's walls.

The survey finding that students studying online use the library's databases more than those students studying in a classroom was reassuring. It suggests that although these students are less likely to visit the library, they are significantly more likely to use the databases for their library research. The UMUC library's resources are fully integrated into the course management sys- 
tem, and instruction of online students has been a priority among the library staff. The survey results suggest that the library's efforts are reaching online students and that the students are aware of the library's resources and use them for their research. However, the survey findings also suggest that finding new means to increase use of these resources among students taking their courses in a classroom remains a challenge for the UMUC library staff.

Another significant trend in the UMUC study is the preponderance of students who are using the free Web and prefer to access resources remotely. At 44.5 percent, use of library databases is lower than expected, compared to 77.6 percent for use of the free Web. The survey results suggest that the free Web is a primary vehicle for research among both undergraduates and graduate students at the university. This finding also follows national trends and indicates that librarians must continue to help students to understand what they have available to them and to help them to make informed decisions on what resources to use. ${ }^{14}$ The concern, expressed by many authors, that students are gravitating to the most readily available Web resource remains an issue for all librarians. The lack of awareness of how much is not available on the Web, and the seeming inability of students to understand why they should use library-supplied databases instead of Web-based sites, remains a significant pedagogical issue that our profession needs to address.

The findings of this study do not indicate that student reliance on online resources and the Web or the decline in the number of students using the physical library has lessened the need for librarians. On the contrary, the authors' research findings suggest that the need for resources, services, and education is greater than ever. Librarians have an essential role to play in developing and delivering resources, services, and instruction to help students become better-informed consumers of information.

The Web poses a challenge, but not an insurmountable one. Librarians must continue to devise new means to deliver their resources, services, and education; and to reach all students to provide them with needed filtering mechanisms to evaluate the quality of the resources they use and to encourage them to become informed consumers, regardless of where or how they obtain their information.

There is a bright spot on the horizon when contemplating the daunting task of reaching diverse student populations taking courses both face-to-face and online, with a preference for electronic resources that are outside the library. A recent article by Mary S. Laskowski found that students are skeptical of the resources they find on the Web and do not appear to be as gullible to the seduction of the Web as many think..$^{15}$ Therefore, there is certainly an opportunity to marshal students' natural skepticism and savvy with the Web into a thoughtful usage approach that helps them make more informed choices about free resources and includes an understanding of the importance of paper and library-supplied databases as well. This study suggests that one of the next steps includes devising additional creative means to meet student needs, wherever they may be, and continuing to enhance education efforts to reach all types of students regardless of how they are taking their courses.

Surveys such as the one conducted by UMUC emphasize that the need for library expertise remains high. The observed student shift to relying more on online resources presents new opportunities to reach students both within and beyond the library's walls, and presents new avenues to illustrate the importance of the librarian's expertise within the campus community.

\section{Notes}

1. Brad McDonald and Robert Dunkelsberger, "Full-text Dependency: An Emerging Trend among Undergraduate Library Users?" Research Strategies 16 (2000): 301-7; Deborah Grimes and 
Carl H. Boening, "Worries with the Web: A Look at Student Use of Web Resources," College and Research Libraries 62 (Jan. 2001): 11-23.

2. Pew Internet \& American Life Project, The Internet Goes to College: How Students Are Living in the Future with Today's Technology, 15 September 2002. Available online from http:// www.pewinternet.org [cited 5 October 2002].

3. Fred R. Van Hartesveldt, "The Undergraduate Research Paper and Electronic Resources: ACautionary Tale," Teaching History 23, no. 2 (1998):51-59; Bonnie Gratch, "Rethinking Instructional Assumptions in an Age of Computerized Information Access," Research Strategies 6 (winter 1988): 4-7.

4. Jonathan J. Kandell, "Internet Addiction on Campus: The Vulnerability of College Students," CyberPsychology \& Behavior 1, no.1 (1998): 14.

5. To see a copy of the survey, please go to http:// polaris.umuc.edu/library/needsassessment.pdf.

6. Council on Library and Information Resources, "The Issue for Presidents and CAOs: Can Academic Users Find Scholarly Resources Online?" CLIRinghouse 6 (Feb. 2002): 1.

7. Laura Stepp, "Point, Click, Think? As Students Rely on the Internet for Research, Teachers Try to Warn of the Web's Snares," Washington Post, 16 July 2002, C01.

8. Daniel Greenstein and Leigh Watson Healy, National Survey Documents Effects of Internet Use on Libraries, April 22, 2002. Available online from http://www.clir.org/pubs/issues/ issues27.html\#national [cited 7 October 2002]; Pew Internet \& American Life Project, The Internet Goes to College.

9. Pew Internet \& American Life Project, The Internet Goes to College.

10. Steven J. Bell, “New Information Marketplace Competitors: Issues and Strategies for Academic Libraries," Portal: Libraries and the Academy 2, no. 2 (2002): 277-303.

11. McDonald and Dunkelsberger, "Full-text Dependency."

12. Grimes and Boening, "Worries with the Web."

13. McDonald and Dunkelsberger, "Full-text Dependency."

14. Gregory A. Crawford and Gary W. White, "Full-text and Libraries: Issues and Implications for Libraries, Librarians, and Library Patrons," National Online Meeting Proceedings (New York: 18th National Online Meeting, 1987).

15. Mary S. Laskowski, "The Role of Technology in Research: Perspectives from Students and Instructors," Portal: Libraries and the Academy 2, no. 2 (2002): 305-19. 